\title{
From Research to Purchase: An Empirical Analysis of Research-Shopping Behaviour in the Insurance Sector*
}

\author{
Stefan Mauł Irena Pletikosa Cvijikj, Joël Wagner ${ }^{\ddagger}$
}

\begin{abstract}
Though almost every insurer provides an integrated solution for online product research and purchase for existing and potentially new customers, there is still a significant percentage of customers turning into research-shoppers, a practice of using one channel for products search and another for purchase. This trend is visible from the channel usage statistics: according to various studies, while more than half of the customers worldwide use the insurers own website for product research, only a minor percentage of them stays there for purchase purposes. The preferred purchase channel often remains the one that enables personal contact to the sales person. This situation is mostly due to the high complexity of the insurance products. In addition, insurance products belong to the category of experience goods, where the evaluation of the product price and characteristics is difficult and can be based only upon previous experience, e.g. after experiencing a claim. While channel switch might lead to higher profit since multichannel customers were found to spend more, the change of the insurer is a serious threat.

In this paper we address this issue and analyse the research-shopper phenomenon in the insurance industry. We investigate which customer and policy characteristics influence the research-shopping behaviour in terms of duration from research conducted via an online channel to purchase conducted using offline channels. Our empirical study was based on a sample of approximately 10000 researchshopper customers of a large Swiss insurance company across the three insurance products: motor, household/liability and travel insurance. The obtained results show that there are several customer characteristics that have an effect over the duration to purchase and that these characteristics differ across different products. Our findings are relevant to academics and practitioners alike and are important for multichannel management and better understanding of the customer journey.
\end{abstract}

Keywords: non-life insurance $\cdot$ multichannel distribution $\cdot$ research-shopping $\cdot$ empirical analysis

\footnotetext{
*This is a post-peer-review, pre-copyedit version of an article published in Zeitschrift für die gesamte Versicherungswissenschaft. The final authenticated version is available online at: https://doi.org/10.1007/s12297-015-0310-1.

${ }^{\dagger}$ Corresponding author.

${ }^{\ddagger}$ Stefan Mau (smau@ethz.ch) and Irena Pletikosa Cvijikj (ipletikosa@ethz.ch) are with the Chair of Information Management, Swiss Federal Institute of Technology Zurich, Weinbergstrasse 56-58, 8092 Zurich, Switzerland. Joël Wagner (joel.wagner@unil.ch) is with the Department of Actuarial Science, Faculty of Business and Economics (HEC), University of Lausanne, Quartier UNIL-Dorigny, Bâtiment Extranef, 1015 Lausanne, Switzerland.
} 


\section{Zusammenfassung}

Trotz der Tatsache, daß eine Vielzahl der Versicherungsunternehmen heutzutage eine integrierte Lösung für Produktrecherche und -kauf im Internet für ihre Kunden implementiert haben, gibt es eine signifikante Anzahl von Research-Shopping-Kunden. Diese Kunden wählen einen präferierten Kanal für die Produktrecherche und wechseln für den Kauf in einen anderen Kanal. Dieses Verhalten wird durch Zahlen aktueller Multichannel-Studien im Versicherungssektor bekräftigt. Gemäß dieser Studien nutzen etwa die Hälfte aller Versicherungskunden die jederzeit verfügbaren Informationen zu Produkten und Preisen im Internet während der Kaufvorbereitung, jedoch nur ein geringer Anteil nutzt den Online-Kanal für den Abschluß der Police. Der bevorzugte Kanal beim Kauf ist weiterhin die Agentur, welche eine persönliche Interaktion mit dem Versicherungsagenten ermöglicht. Gründe dafür liegen sicher in der hohen Komplexität von Versicherungsprodukten, deren Güte und Wert beim Kauf durch den Kunden nur bei vorhandener Produkterfahrung einschätzbar sind. Des weiteren haben Studien gezeigt, daß die Nutzung multipler Kanäle durch Kunden mit einem erhöhten Umsatz einhergeht. Es besteht dabei jedoch die Gefahr, den Kunden auf dem Weg zwischen Internet und Agentur zu verlieren.

In dieser Studie adressieren wir diesen Sachverhalt und analysieren das Research-Shopping- Verhalten im Versicherungssektor. Genauer untersuchen wir den Einfluß von Kunden- und Policencharakteristika auf die Zeitdauer, welche der Kunde zwischen Online-Recherche und Offline-Kauf auf der Agentur benötigt. Unsere Analyse basiert auf einem Datensatz von ca. 10000 Research-ShoppingKunden einer Schweizer Versicherung und beinhaltet die Produkte: Motorfahrzeug-, Hausrat- und Privathaftpflicht- sowie Reiseversicherung. Die Ergebnisse der Studie zeigen, welche Charakteristika einen Einfluß auf die Zeitdauer bis zum Kauf haben. Diese variieren je nach Versicherungsprodukt. Unsere Ergebnisse sind gleichermaßen relevant für Forschung und Versicherungsindustrie: Sie tragen sowohl zu einer Verfeinerung des Multichannel-Managements, als auch zu einem besseren Verständnis der Customer-Journey bei.

Keywords: Nicht-Leben Versicherungen · Multichannel Vertrieb · Research-Shopping · Empirische Analyse 


\section{Introduction}

Establishment of digital distribution channels in the insurance sector has changed the customer behaviour resulting in different patterns of channel usage. As an outcome, customers start frequently using more than one channel during the shopping process. Yet, according to the study by SwissRe (2012), the overall market in the European Union in 2012 had a ratio of online sales of $14 \%$, whereas the ratio of insurance policies sold through the online channel was less than $5 \%$. Thus, on the European market, the penetration of online channels for purchase of insurance products is still lower compared to other product categories. In contrast, online channels represent a popular medium for insurance customers to perform research regarding different product characteristics and pricing possibilities prior to conducting the actual purchase. Moreover, the Internet was found to be the most utilized channel to conduct research for insurance products (SwissRe, 2012). A similar behaviour was found to exist for the US customers, where $73 \%$ of customers were conducting online research for motor insurance (McKinsey, 2012). These figures suggest that majority of insurance customer are turning to a shopping pattern known as researchshopping, which refers to the practice of using one channel for product search and another for purchase Verhoef et al. (2007). Moreover, Verhoef et al. (2007) show that researching on the Internet and purchasing offline, called Internet $\rightarrow$ Store, is the most common form of research-shopping behaviour.

With the growing number of multichannel customers, researchers have turned their attention to understanding the opportunities and challenges of multichannel customer management. For example, Stone et al. (2002) identify the opportunities for providing improved experience, reducing churn rates, improving the brand perception and thus mitigating the risk of brand damage. These factors potentially lead to the main goal, i.e. the possibility for gaining higher profits (Stone et al., 2002). In compliance with these expectations, multichannel customers were found to spend more compared to single channel customers (Kumar and Venkatesan, 2005; Venkatesan et al., 2007). However, recent studies reveal that this type of behaviour applies only for hedonic and low-risk product categories while in the case of utilitarian and high-risk products, pure online customers represent the most valuable segment (Kushwaha and Shankar, 2013). Apart from potential benefits, the multichannel environment also imposes certain challenges, one of those being the fact that companies might lose their customers during the channel switching, a phenomenon known as free-riding (Chiu et al., 2011; Nunes and Cespedes, 2003; Rangaswamy and Van Bruggen, 2005). In addition, similar to the case of profit gain, free-riding behaviour is found to differ across different product categories, yet socio-demographic characteristics of customers who engage in free-riding are shown to be the same across different product categories (Heitz-Spahn, 2013).

Research-shopper behaviour is of great importance for the insurance sector due to the growing popularity of online aggregators used for product search, as well as the fact that price consciousness is shown to be one of the main drivers for online channel utilization (Konus et al., 2008; Noble et al., 2005; Verhoef et al., 2007). Thus timely reaction from the company to online calculations conducted by their potential customers might overcome the challenge of free-riding. First step towards understanding the research-shopper behaviour could be to determine the characteristics of the customers who are more likely to engage in such behaviour and their potential differences across product categories. While prior studies focus mostly on retailers (e.g. Heitz-Spahn, 2013; Van Baal and Dach, 2005; Verhoef et al., 2007), research 
in the domain of multichannel behaviour in the insurance industry is relatively limited. Few studies address questions such as multiple channels co-existence and potential cannibalization (Berger et al., 1997; Trigo-Gamarra, 2008), multichannel strategies (Stone et al., 1997; Trigo-Gamarra and Growitsch, 2010), conflict management (Cather and Howe, 1989), influencers for channel selection (Dall'Olmo Riley et al., 2009), or customer segmentation (Konus et al., 2008). To the best of our knowledge, the research-shopper phenomenon in the insurance sector has not been studied yet.

The contribution of this paper is as follows. We address the issue of research-shopping in the insurance industry and investigate the research-shopper behaviour. Thereby we focus on the customer and policy characteristics which influence the behaviour across the three most common non-life insurance products, i.e. motor, household/liability and travel insurance. Moreover, we look into the duration between research and purchase to determine the optimal time span in which company should react in order to retain potential customers.

In the continuation, this paper is structured as follows. First in Section 2, we provide an overview of the previous work in related research area and derive our hypotheses. Next, we provide a description of the applied methodology in Section 3. Consequently, we present the results and discuss our findings from the perspective of implications for research and practice in Sections 4, 5. In Section 6 we conclude with a summary and an outlook on future research.

\section{Literature Review and Hypotheses}

With the increasing number of channels offered by the companies to their customers in order to improve their interaction and shopping experiences, the need for multichannel customer management emerged. Multichannel customer management can be seen as a practice which involves "... design, deployment, coordination, and evaluation of channels through which firms and customers interact, with the goal of enhancing customer value through effective customer acquisition, retention, and development." (Neslin et al., 2006) As such, it was soon recognized as a necessity in the new market environment and has thus received lots of attention from both scholars and practitioners.

Multichannel customer management has already been subjected to many studies spanning across topics from identifying the characteristics of multichannel customers and their segments (e.g. Elliott et al., 2012; Konus et al., 2008; Kumar and Venkatesan, 2005), understanding the factors which drive channel adoption (e.g. Balasubramanian et al., 2005; Kumar and Venkatesan, 2005; Venkatesan et al., 2007), migration across channels during the shopping process (e.g. Ansari et al., 2008; Gupta et al., 2004; Venkatesan et al., 2007; Verhoef et al., 2007), the value of multichannel customers (e.g. Ansari et al., 2008; Kumar and Venkatesan, 2005; Venkatesan et al., 2007), etc. Yet, there are still many challenges and open questions to be addressed (Neslin and Shankar, 2009; Rangaswamy and Van Bruggen, 2005; Stone et al., 2002).

Among the topics of interest is the understanding of the customers behaviour who utilize one channel for research and another for purchase, a phenomena known as research-shopping (Verhoef et al., 2007). The importance of this topic emerges form a generally adopted knowledge that customers utilizing more than one channel are more profitable than single channel customers (Neslin and Shankar, 2009). Yet, 
it should be taken in consideration that this reasoning might not apply to every channel combination, however using an additional channel during the shopping process was still shown to result in greater customer value (Thomas and Sullivan, 2005). In addition, research-shopping, if not managed well, could potentially lead to losing a customer in his course of switching among channels between research and purchase stages (Nunes and Cespedes, 2003; Verhoef et al., 2007).

In their study, Verhoef et al. (2007) approach research-shopping from the perspective identifying different patterns of channel switching and reveal that Internet $\rightarrow$ Store is the most common form of research-shopping. In addition, they look into the factors which lead to research-shopping behaviour, identifying (1) the lack of lock-in for a given channel, and (2) a strong positive synergy between two channels, as main drivers for channel switching. In addition, (3) attribute differences between channels could lead to choosing different channels for different shopping stages. Yet, the question remains whether this kind of behaviour should be encouraged or discouraged (Neslin and Shankar, 2009; Verhoef et al., 2007). This question is of particular importance since Internet $\rightarrow$ Store research-shopping could be considered positive only, if the vendor is able to integrate "Internet" and "Store" well enough, so that it directs the customers to the store.

Further classification of research-shopper behaviour was proposed by Neslin and Shankar (2009) who classified the shoppers using two dimensions (1) switching between channels for research and purchase, and (2) switching between different companies for research and purchase. The resulting shopper types are listed in Table 1.

Tabelle 1: Research-shopper types according to Neslin and Shankar (2009).

\begin{tabular}{lll}
\hline Channel for search & Channel of purchase & Shopper type \\
\hline Channel A of Firm 1 & Channel B of Firm 2 & Competitive research-shopper \\
Channel A of Firm 1 & Channel B of Firm 1 & Loyal research-shopper \\
Channel A of Firm 1 & Channel A of Firm 1 & One-stop shopper \\
\hline
\end{tabular}

According to Neslin and Shankar (2009), the main challenge in a multichannel environment is to design individual channels in a way which would lead to growth of loyal research-shoppers and conversion of onestop shoppers to loyal research-shoppers. Similarly, looking into the same dimensions of research-shopping behaviour, Chiu et al. (2011) identify four patterns of research-shopping: within-channel switching, crosschannel free-riding, within-channel retention and cross-channel retention. Of those, avoiding cross-channel free-riding is of the greatest concern for the companies. Finally, Elliott et al. (2012) propose a more general categorization which distinguishes between pure onliners, pure offliners, cross-channel onliners, crosschannel offliners, dual-search onliners and dual-search offliners. Of those, cross-channel and dual-channel onliners and offliners belong to the group of research-shoppers.

In order to be able to address the previously listed challenges, companies should strive to achieve complete customer data integration (CDI) across all channels (Neslin et al., 2006). This approach would enable access to the operative data needed to detect multichannel customer behaviour, and in particular for the loyal research-shoppers and one-stop shoppers. However, monitoring of competitive research-shopper behaviour would be difficult, if not impossible, since it would require access to competitors' data sources. 
Apart from looking into the channel characteristics which drive research-shopping behaviour, studies were conducted to understand the specific customer characteristics which could lead to a certain type of customer behaviour in the multichannel environment. For example, Schoenbachler and Gordon (2002) propose a model which estimates the likelihood that a customer will purchase from a particular channel or from multiple channels. The proposed model integrates five main factors: the perceived risk, past direct marketing experience, motivation to buy from a channel, product category and web site design. Of those, the motivation to buy from a channel depends among others on the customer demographics, such as age, gender, income, education, occupation, and number of household members. Still, this study is only conceptual and does not provide empirical evidence for the given statements. In turn, Konus et al. (2008) provide empirical evidence for the model determining multichannel shopper segments. Building upon previous literature they derive a list of socio-demographic (age, education, household, income, urbanicity and welfare) and psychographic factors (price consciousness, loyalty, shopping enjoyment, innovativeness, time pressure, and motivation to conform) which are assumed to differ across multichannel shopper segments. Their results indicate that innovativeness, loyalty and shopping enjoyment represent significant factors, while no significant differences were found to exist in terms of the demographic factors. Still, a deeper analysis across different product categories revealed significant differences in terms of age, gender, urbanicity, education and income. Similarly, Kushwaha and Shankar (2013) state that age, education and family size play a significant role for distinguishing between multichannel customers, while according to Ansari et al. (2008), multichannel customers are more likely to be younger, have higher income and live in a family with children.

In the domain of the insurance sector, Elliott et al. (2012) studied research and purchase patterns for the motor insurance. The authors found that age and ethnicity vary significantly over their observed channels, i.e. multichannel customers were shown to be younger and non-White, while gender, education, marital status and income are not associated with the multichannel behaviour. Further, Yang (2015) investigated the difficulties customers encounter, when forming insurance decisions using self-service technology channels, such as the Internet, for the Taiwan market. The findings show that middle aged customers with high income are more likely to purchase insurance over self-service technology channels, indicating an impact of customer demographics on multichannel behaviour.

The literature review provided in this section indicates that although the effect of demographic factors has already been addressed in several previous studies, the results are still inconclusive, with some authors reporting a significant effect of certain factors while other denying it. Thus, to gain a better understanding of the specific characteristics of multichannel behaviour, an in particular in the insurance sector, further investigation is needed. Moreover, most of the previous studies based their findings on online surveys. This approach has been seen criticized by some authors (e.g. Soopramanien and Robertson, 2007; Bhatnagar and Ghose, 2004; Li et al., 1999), who state that online surveys usually show a consistent higher percentage of internet buyers, which could introduce a systematic bias into the sample respresentativeness, leading to varying frequency distributions for the customer characteristics.

To address these issues, in this paper we follow the call for research posed by Neslin and Shankar (2009) to "Determine how to maximize profits from competitive and loyal research-shoppers?"We focus on the insurance sector which has not been studied in depth. We use a sample obtained from a large 
From Research to Purchase: Shopping Behaviour in the Insurance Sector

Swiss insurer containing 9791 observations from the year 2013, and we look into the customer and policy characteristics which influence the research-shopper behaviour across three common non-life insurance products: motor, household/liability and travel insurance. Since the major challenge for companies is to avoid customer loss in the course of channel switching during the research-shopping, we look into the duration between research and purchase to determine the optimal time span in which a company could react in order to retain potential customers. Building upon the general understanding that demographic characteristics play an important role for multichannel customer behaviour (Neslin and Shankar, 2009), we propose the following hypothesis $(\mathrm{H} 1)$ :

Hypothesis 1: Customer and policy characteristics have an influence on the research-shopping behaviour of insurance customers, in specific over the duration between product research and product purchase.

In addition, building upon the knowledge from other industry sectors that product category plays a significant role for channel choice and thus consequently influences multichannel behaviour (e.g. Schoenbachler and Gordon, 2002), we propose another hypothesis (H2):

Hypothesis 2: Customer and product-specific policy characteristics have an influence on the researchshopping behaviour of insurance customers, in specific over the duration between product research and product purchase.

\section{Research Design}

In this section we first describe the context of the research and the dataset that is used. Then we specify with more details the available variables and lay out the methodology used to derive the results.

\subsection{Context and Dataset}

We verify our hypotheses on the hand of a sample of customer and policy data directly obtained from the data warehouse of a large Swiss insurer. The company sells a broad range of life and non-life insurance products in all regions of Switzerland and is one of the top three non-life insurers in the Swiss market. The carrier mainly sells policies via traditional channels, such as exclusive agencies and brokers. In addition, since 2009 an online channel is established that provides possibility for purchase of the three most common non-life insurance products, that are motor, household/liability and travel insurance. The multichannel and marketing strategy of the company is a single brand and one price approach over all distribution channels.

The dataset used in this study includes policies for the three afore mentioned non-life insurance products. The research-shopping behaviour of the insurance customers in this sample is detected by applying a proprietary matching technique within the insurance company. For the detection procedure, the pricing relevant attributes of online quotes are matched to those of booked policies sold via offline channels after the research date. The dataset includes policies purchased in 2013, and is limited to loyal research-shoppers (Neslin and Shankar, 2009). In the set of $N=9791$ observations in total, the largest 
subsample is represented by motor insurance policies with $n=5891$ observations. These are followed by $n=2773$ household/liability policies and travel insurance represented by $n=1127$ observations.

\subsection{Variables}

For each observation, the following factors are in our initial interest and appear across all three insurance products: the date of research on the website, the date of purchase at an agency, the customer's age $(A G E)$ in years, its gender $(G E N)$, and nationality $(N A T)$, the urbanicity $(U R B)$ of the residence area of the customer, the customer status $(C S T)$, indicating whether a policyholder is either an existing customer and has already purchased another insurance product, or a new customer, and finally the policy status (PST), indicating whether an existing policy is changed/replaced or initially purchased. In order to address the issues laid out in Hypothesis (H2), the insurance product $(P R O)$ is taken in consideration.

In addition to the attributes of the overall sample, the motor insurance subsample includes the following covariates: the number of years the driving license is hold by the customer $(D L S)$, the type of vehicle to be insured $(T V C)$, distincting between motorcycles and passenger cars, and the age of the vehicle $(A V C)$ in years. Further, within the houshold/liability subsample, in addition to the general variables, the following covariates are added: the type of household $(T H H)$, distinguishing between singles' or couples' households, the information about the number of children in the household $(K H H)$, the ownership situation $(O W N)$, dividing between renters and owners, and the sum assured $(S A S)$, representing the value of the possessions within the household which are assured in the policy (in thousands of CHF). Finally, for the analysis of travel insurance, two further covariates were added: the type of household $(T H H)$ and the number of children in the household $(K H H)$. Table 2 gives a summary of the variables used.

\subsection{Methodology}

\section{Duration between Research and Purchase}

As mentioned above, we aim to investigate the impact of the customer characteristics on a specific research-shopper behaviour and in particular, the duration $\delta$ between the time $t_{0}$ of product research on the internet and the time $t_{1}$ of purchase at the agency. Therefore, we measure the number of workdays between the two events as follows :

$$
\delta=t_{1}-t_{0}
$$

\section{Survival Analysis}

In order to estimate the time of potential product purchase after the research has been conducted on the online channel, we apply survival analysis, a method suitable for making predictions regarding the duration until the occurrence of a subsequent event. In particular, we use a Cox model which explored the relation between the survival and a set of relevant features (Cox, 1972). For the task at hand, we look into the effect of customer characteristics on the duration between research and purchase. The survival function of the corresponding Cox model is defined as the probability that no event will occur between 
Tabelle 2: Summary of the variables used in the data analyses.

\begin{tabular}{lll}
\hline Attribute & Variable & Values \\
\hline Overall variables & & \\
Date of research & $t_{0}$ & date of research on the website \\
Date of purchase & $t_{1}$ & date of purchase at an agency \\
Customer age & $A G E$ & age of the customer within one of 6 age classes \\
Customer gender & $G E N$ & gender of the customer: male, female \\
Customer nationality & $N A T$ & nationality of the customer: Swiss, non-Swiss \\
Customer urbanicity & URB & urbanicity of the customer's residence area: rural, urban \\
Customer status & $C S T$ & existing customer, new customer \\
Policy status & $P S T$ & replaced policy, new policy \\
Product & $P R O$ & motor, household/liability, travel \\
\hline Additional variables for motor & insurance & \\
Drivers license since & $D L S$ & number of years driving license is hold \\
Type of vehicle & $T V C$ & motor cycle, passenger car \\
Age of vehicle & $A V C$ & age of the vehicle in years \\
\hline Additional variables for household/liability insurance & \\
Type of household & THH & singles, couples \\
Number of children & KHH & number of children in the household \\
Ownership & OW $N$ & renters, owners \\
Sum assured & SAS & value of household possessions insured (in kCHF) \\
\hline Additional variables for travel insurance & THH & \\
Type of household & KHH & singles, couples \\
Number of children & number of children in the household \\
\hline
\end{tabular}

time $0\left(t_{0}\right)$ and time $t$, and is given by the following formula:

$$
S(t ; x)=\left[S_{0}(t)\right]^{\exp \left(x^{\prime} \beta\right)}
$$

where $t$ is the time of the event, $x$ is a $1 \times n$ vector of covariates containing the values $\left(x_{1}, x_{2}, \ldots, x_{n}\right)^{\prime}$, and $\beta$ is a vector of coefficients to be estimated. Further, $S_{0}(t)$ is the baseline survival function, which can be understood as the survival function for the case that all covariates are scaled to zero, see, e.g., Liu (2012).

To verify hypothesis (H1), all characteristics of the overall sample containing all three products are included in the covariates vector of the Cox model. Thereby, the vectors of covariates and estimated coefficients are defined as follows (the subscripts $i$ refer to the possible values taken by the variables, see Table 2):

$$
\begin{aligned}
x_{\text {all }}^{\prime} \beta_{\text {all }}= & \sum_{i=1}^{6} \beta_{1 i} A G E_{i}+\sum_{i=1}^{2} \beta_{2 i} G E N_{i}+\sum_{i=1}^{2} \beta_{3 i} N A T_{i}+\sum_{i=1}^{2} \beta_{4 i} U R B_{i}+\sum_{i=1}^{2} \beta_{5 i} C S T_{i} \\
& +\sum_{i=1}^{2} \beta_{6 i} P S T_{i}+\sum_{i=1}^{3} \beta_{7 i} P R O_{i}
\end{aligned}
$$


Further, to verify hypothesis (H2), the vector containing general customer characteristics defined in Formula (3) is extended by product-specific characteristics for each of the three analysed products, motor insurance (subscript "motor"), household/liability insurance (subscript "hh/li") and travel insurance (subscript "trav"). The resulting formulas write out as follows:

$$
\begin{aligned}
x_{\text {motor }}^{\prime} \beta_{\text {motor }}= & \sum_{i=1}^{6} \beta_{1 i} A G E_{i}+\sum_{i=1}^{2} \beta_{2 i} G E N_{i}+\sum_{i=1}^{2} \beta_{3 i} N A T_{i}+\sum_{i=1}^{2} \beta_{4 i} U R B_{i}+\sum_{i=1}^{2} \beta_{5 i} C S T_{i} \\
& +\sum_{i=1}^{2} \beta_{6 i} P S T_{i}+\sum_{i=1}^{6} \beta_{7 i} D L S_{i}+\sum_{i=1}^{2} \beta_{8 i} T V C_{i}+\sum_{i=1}^{4} \beta_{9 i} A V C_{i} \\
x_{\mathrm{hh} / \mathrm{li}}^{\prime} \beta_{\mathrm{hh} / \mathrm{li}}= & \sum_{i=1}^{6} \beta_{1 i} A G E_{i}+\sum_{i=1}^{2} \beta_{2 i} G E N_{i}+\sum_{i=1}^{2} \beta_{3 i} N A T_{i}+\sum_{i=1}^{2} \beta_{4 i} U R B_{i}+\sum_{i=1}^{2} \beta_{5 i} C S T_{i} \\
& +\sum_{i=1}^{2} \beta_{6 i} P S T_{i}+\sum_{i=1}^{2} \beta_{7 i} T H H_{i}+\sum_{i=1}^{4} \beta_{8 i} K H H_{i}+\sum_{i=1}^{2} \beta_{9 i} O W N_{i}+\sum_{i=1}^{9} \beta_{10 i} S A S_{i} \\
x_{\text {trav }}^{\prime} \beta_{\text {trav }}= & \sum_{i=1}^{6} \beta_{1 i} A G E_{i}+\sum_{i=1}^{2} \beta_{2 i} G E N_{i}+\sum_{i=1}^{2} \beta_{3 i} N A T_{i}+\sum_{i=1}^{2} \beta_{4 i} U R B_{i}+\sum_{i=1}^{2} \beta_{5 i} C S T_{i} \\
& +\sum_{i=1}^{2} \beta_{6 i} P S T_{i}+\sum_{i=1}^{2} \beta_{7 i} T H H_{i}+\sum_{i=1}^{4} \beta_{8 i} K H H_{i}
\end{aligned}
$$

\section{Results}

In this section we present our results. First we give descriptive statistics on the dataset, then we analyse the duration between the times of research and purchase. In the last subsection we report the survival analysis.

\subsection{Descriptive Statistics}

The results of the descriptive analysis over the complete sample provided in Table 3 reveal that researchshoppers are younger customers, with the modal category being the one including customers of age between 25 and 34 years (39.4\%). The sample consists mainly of male (59.0\%), Swiss customers (87.5\%), and is almost equally distributed between urban and rural areas of residence. Furthermore, existing customers engage in research-shopping more frequently $(65.0 \%)$, and in order to purchase new policies $(64.4 \%)$. In the continuation, characteristics and subsample summaries for each of the three analysed products are presented.

\section{Motor Insurance}

Within the motor insurance subsample (see Table 4), the customers age distribution looks similar to the 
Tabelle 3: Sample summary for all products $(N=9791)$.

\begin{tabular}{|c|c|c|c|c|c|c|c|c|}
\hline Characteristics & Frequency & Percentage & Characteristics & Frequency & Percentage & Characteristics & Frequency & Percentage \\
\hline Age & & & Nationality & & & Policy Status & & \\
\hline$<25$ & 2292 & $(23.4 \%)$ & Non-Swiss & 1219 & $(12.5 \%)$ & Replaced Policy & 3489 & $(35.6 \%)$ \\
\hline $25-34$ & 3859 & $(39.4 \%)$ & Swiss & 8572 & $(87.5 \%)$ & New Policy & 6302 & $(64.4 \%)$ \\
\hline $35-44$ & 1713 & $(17.5 \%)$ & Urbanicity & & & Product & & \\
\hline $45-54$ & 1124 & $(11.5 \%)$ & Rural & 5428 & $(55.4 \%)$ & Motor & 5891 & $(60.2 \%)$ \\
\hline $55-64$ & 531 & $(5.4 \%)$ & Urban & 4363 & $(44.6 \%)$ & Household/Liab. & 2773 & $(28.3 \%)$ \\
\hline$\geq 65$ & 272 & $(2.8 \%)$ & Customer Status & & & Travel & 1127 & $(11.5 \%)$ \\
\hline Gender & & & Existing Cust. & 6361 & $(65.0 \%)$ & & & \\
\hline Male & 5780 & $(59.0 \%)$ & New Customer & 3430 & $(35.0 \%)$ & & & \\
\hline Female & 4011 & $(41.0 \%)$ & & & & & & \\
\hline
\end{tabular}

Tabelle 4: Sample summary for the motor insurance product $(n=5891)$.

\begin{tabular}{|c|c|c|c|c|c|c|c|c|}
\hline Characteristics & Frequency & Percentage & Characteristics & Frequency & Percentage & Characteristics & Frequency & Percentage \\
\hline Age & & & Urbanicity & & & Age of Vehicle & & \\
\hline$<25$ & 1529 & $(26.0 \%)$ & Rural & 3590 & $(60.9 \%)$ & $<1$ & 1578 & $(26.7 \%)$ \\
\hline $25-34$ & 2289 & $(38.9 \%)$ & Urban & 2301 & $(39.1 \%)$ & $1-4$ & 1490 & $(25.3 \%)$ \\
\hline $35-44$ & 1038 & $(17.6 \%)$ & Drivers License since & & & $5-9$ & 1364 & $(23.2 \%)$ \\
\hline $45-54$ & 650 & $(11.0 \%)$ & $<1$ & 824 & $(14.0 \%)$ & $\geq 10$ & 1459 & $(24.8 \%)$ \\
\hline $55-64$ & 297 & $(5.0 \%)$ & $1-4$ & 994 & $(16.9 \%)$ & Customer Status & & \\
\hline$\geq 65$ & 88 & $(1.5 \%)$ & $5-9$ & 1221 & $(20.7 \%)$ & Existing Cust. & 3930 & $(66.7 \%)$ \\
\hline Gender & & & $10-19$ & 1439 & $(24.4 \%)$ & New Customer & 1961 & $(33.3 \%)$ \\
\hline Male & 3552 & $(60.3 \%)$ & $20-29$ & 811 & $(13.8 \%)$ & Policy Status & & \\
\hline Female & 2339 & $(39.7 \%)$ & $\geq 30$ & 602 & $(10.2 \%)$ & Replaced Policy & 2222 & $(37.7 \%)$ \\
\hline Nationality & & & Type of Vehicle & & & New Policy & 3669 & $(62.3 \%)$ \\
\hline Non-Swiss & 752 & $(12.8 \%)$ & Motorcycle & 847 & $(14.4 \%)$ & & & \\
\hline Swiss & 5139 & $(87.2 \%)$ & Passenger Car & 5044 & $(85.6 \%)$ & & & \\
\hline
\end{tabular}

one of the complete sample. The same applies for gender, nationality, policy status, and customer status. Looking at the product specific characteristics one can state that, the age of vehicles insured is almost equally distributed across all categories. The sample has a larger portion of passenger cars (85.6\%) and the drivers are more experienced with over $65 \%$ of them having their license for more than five years. Table 4 provides the details for each of the observed factors.

\section{Household/Liability Insurance}

Further, the customers who have purchased household/liability insurance policies (see Table 5 for the full descriptive statistics) were found to have a higher ratio of 25 to 34 years old people with $42.8 \%$, but a lower ratio of those being below 25 years old (20.7\%) compared to the complete sample. In addition, the ratios of new customers (45.8\%), those living in urban areas (56.8\%), and those replacing existing policies $(41.5 \%)$ are higher than in the complete sample. In turn, the distribution of gender and nationality look similar to the complete sample distribution. Looking at the product specific attributes, the majority of the customers have no children $(86.8 \%)$ and are renting their homes $(82.9 \%)$, which correlates with the higher ratio of households inhabited by singles (56.5\%). Finally, over $65 \%$ of the customers have a sum assured below CHF 75000 .

\section{Travel Insurance}

Finally, the observations related to the travel insurance product indicate that the product is most frequently purchased by research-shoppers who are between 25 and 34 years old (34.1\%). Compared to the 
From Research to Purchase: Shopping Behaviour in the Insurance Sector

Tabelle 5: Sample summary for the household/liability insurance product $(n=2773)$.

\begin{tabular}{|c|c|c|c|c|c|c|c|c|}
\hline Characteristics & Frequency & Percentage & Characteristics & Frequency & Percentage & Characteristics & Frequency & Percentage \\
\hline Age & & & Policy Status & & & Sum assured & & \\
\hline$<25$ & 574 & $(20.7 \%)$ & Replaced Policy & 1152 & $(41.5 \%)$ & $<30$ & 408 & $(14.7 \%)$ \\
\hline $25-34$ & 1186 & $(42.8 \%)$ & New Policy & 1621 & $(58.5 \%)$ & $30-44$ & 565 & $(20.4 \%)$ \\
\hline $35-44$ & 476 & $(17.2 \%)$ & Number of Children & in Househ & & $45-59$ & 477 & $(17.2 \%)$ \\
\hline $45-54$ & 283 & $(10.2 \%)$ & No Children & 2408 & $(86.8 \%)$ & $60-74$ & 352 & $(12.7 \%)$ \\
\hline $55-64$ & 151 & $(5.4 \%)$ & 1 Child & 190 & $(6.9 \%)$ & $75-89$ & 213 & $(7.7 \%)$ \\
\hline$\geq 65$ & 103 & $(3.7 \%)$ & 2 Children & 136 & $(4.9 \%)$ & $90-104$ & 234 & $(8.4 \%)$ \\
\hline Gender & & & 3 or more & 39 & $(1.4 \%)$ & $105-124$ & 147 & $(5.3 \%)$ \\
\hline Male & 1599 & $(57.7 \%)$ & Type of Household & & & $125-149$ & 204 & $(7.4 \%)$ \\
\hline Female & 1174 & $(42.3 \%)$ & Singles & 1568 & $(56.5 \%)$ & $\geq 150$ & 173 & $(6.2 \%)$ \\
\hline Nationality & & & Couples & 1205 & $(43.5 \%)$ & Customer Status & & \\
\hline Non-Swiss & 405 & $(14.6 \%)$ & Ownership & & & Existing Cust. & 1504 & $(54.2 \%)$ \\
\hline Swiss & 2368 & $(85.4 \%)$ & Renter & 2300 & $(82.9 \%)$ & New Customer & 1269 & $(45.8 \%)$ \\
\hline Urbanicity & & & Owner & 473 & $(17.1 \%)$ & & & \\
\hline Rural & 1199 & $(43.2 \%)$ & & & & & & \\
\hline Urban & 1574 & $(56.8 \%)$ & & & & & & \\
\hline
\end{tabular}

Tabelle 6: Sample summary for the travel insurance product $(n=1127)$.

\begin{tabular}{|c|c|c|c|c|c|c|c|c|}
\hline Characteristics & Frequency & Percentage & Characteristics & Frequency & Percentage & Characteristics & Frequency & Percentage \\
\hline Age & & & Nationality & & & Urbanicity & & \\
\hline$<25$ & 189 & $(16.8 \%)$ & Non-Swiss & 62 & $(5.5 \%)$ & Rural & 639 & $(56.7 \%)$ \\
\hline $25-34$ & 384 & $(34.1 \%)$ & Swiss & 1065 & $(94.5 \%)$ & Urban & 488 & $(43.3 \%)$ \\
\hline $35-44$ & 199 & $(17.7 \%)$ & \multicolumn{3}{|c|}{ Number of Children in Household } & Customer Status & & \\
\hline $45-54$ & 191 & $(16.9 \%)$ & No Children & 951 & $(84.4 \%)$ & Existing Cust. & 927 & $(82.3 \%)$ \\
\hline $55-64$ & 83 & $(7.4 \%)$ & 1 Child & 71 & $(6.3 \%)$ & New Customer & 200 & $(17.7 \%)$ \\
\hline$\geq 65$ & 81 & $(7.2 \%)$ & 2 Children & 82 & $(7.3 \%)$ & Policy Status & & \\
\hline Gender & & & 3 or more & 23 & $(2.0 \%)$ & Replaced Policy & 115 & $(10.2 \%)$ \\
\hline Male & 629 & $(55.8 \%)$ & Type of Household & & & New Policy & 1012 & $(89.8 \%)$ \\
\hline \multirow[t]{2}{*}{ Female } & 498 & $(44.2 \%)$ & Singles & 613 & $(54.4 \%)$ & & & \\
\hline & & & Couples & 514 & $(45.6 \%)$ & & & \\
\hline
\end{tabular}

figures for motor and household/liability products, this represents the lowest value in the complete sample. Furthermore, for this product a higher ratio of female customers is visible $(44.2 \%)$, and the sample is dominated by Swiss customers (94.5\%). The distribution of urbanicity looks equal to the one of the complete sample. Moreover this product seems to be popular for cross-selling, which is indicated through the high ratio of existing customers (82.3\%). Due to their simplicity compared to other insurance products, this product once purchased hardly requires an adaptation, thus the high ratio of new policies $(89.8 \%)$ is not surprising. In regard to the product specific factors, $84.4 \%$ of the customers have no children, with an almost equal distribution between households inhabited by singles $(54.4 \%)$ or couples $(45.6 \%)$. Table 6 provides the details for each of the observed factors.

\subsection{Duration between Research and Purchase}

In Table 7 we provide our results on the duration of the time span between research and purchase. In general, we find that the customers needed an average of 19.74 workdays $(S D=18.26)$ to purchase a policy after conducting research on the online channel. Further, no significant difference $(t(5201.68)=$ $.65, p=.51)$ was found to exist between the duration to purchase for products motor $(M=20.41, S D=$ $18.00)$ and household/liability $(M=20.13, S D=18.89)$, while customers purchasing travel insurance were faster $(M=15.33, S D=17.37)$ compared to motor $(t(1623.17)=8.94, p<.001)$ and household/liability 
Tabelle 7: Descriptive results for the duration (in workdays) from research to purchase.

\begin{tabular}{lccrr}
\hline & Overall & Motor & $\begin{array}{c}\text { Household/ } \\
\text { Liability }\end{array}$ & Travel \\
\cline { 2 - 4 } & & & \\
Mean $(M)$ & 19.74 & 20.41 & 20.13 & 15.33 \\
Standard Deviation $(S D)$ & 18.26 & 18.00 & 18.89 & 17.37 \\
Median $(M d n)$ & 13.50 & 14.50 & 13.50 & 8.50 \\
\hline
\end{tabular}

$(t(2256.58)=7362, p<.001)$. The mean value of the duration is found to be greater than the median in motor and household/liability insurance products, indicating that there is a tail in the cumulative distribution function and that the majority of the customers turned towards the agency within the first days after the research was conducted on the company's website.

\subsection{Survival Analysis}

The coefficients of the Cox model for the complete sample determine the impact of the measured characteristics over the duration to purchase. The product variable $(P R O)$ is found to have a significant impact over the duration to purchase. Compared to the travel insurance product that we use as a baseline, the coefficients for motor $(\beta=-.215, p<.001)$ and household/liability $(\beta=-.195, p<.001)$ insurance products indicate a negative effect, i.e. the duration to purchase is prolonged. This is not surprising since the two products are significantly more complex than the travel insurance product. When looking at the age variable, the figures reveal that customers who were less than 25 years old made their purchase within the shortest time since the online search. Thus, the coefficients for all other age groups are negative. In addition, for customers between 35 and 44 years $(\beta=-.102, p<.01)$ and those between 45 and 54 $(\beta=-.074, p<.05)$ the effect is found to be significant. In regard to the remaining factors, being a new customer, a female, having Swiss nationality, and living in an urban area were found to have a positive but not significant effect on the duration. Finally, purchasing a new policy of a particular product is also found to have a strong positive impact $(\beta=.319, p<.001)$ the duration. The likelihood ratio statistic of the model indicates a significant fit $\left(\chi^{2}(12, N=9791)=358.028, p<.001\right)$ with an $R^{2}=.036$. Table 8 provides an overview into the obtained coefficients and their significance levels.

\section{Motor Insurance}

Table 9 provides an overview of the obtained results for the different insurance products. Similar results than the overall are obtained regarding the age variable $(A G E)$. Again the negative sign of all coefficients for the age categories indicates that the youngest customers have the shortest duration to purchase. Moreover, customers from age categories between 25 and 34 years $(\beta=-.112, p<.05)$, as well as those between 35 and 44 years $(\beta=-.154, p<.05)$ have a significant effect. For this product, the gender is found to have a significant effect suggesting that female customers are making their purchase faster than men $(\beta=.076, p<.01)$. Further, for Swiss, new customers, and those living in urban areas the coefficients are found to have a positive, but not significant effect over the duration to purchase. In 
From Research to Purchase: Shopping Behaviour in the Insurance Sector

Tabelle 8: Coefficients of the Cox model for all insurance products $(N=9791)$.

\begin{tabular}{|c|c|c|c|c|c|}
\hline Characteristics & $\beta$ & $\exp (\beta)$ & $S E$ & $Z$ & $p$ \\
\hline \multicolumn{6}{|l|}{ Product } \\
\hline Travel & baseline & & & & \\
\hline Motor & $-0.2153^{* * *}$ & 0.8063 & 0.0345 & -6.2369 & $<.001$ \\
\hline Household/liability & $-0.1945^{* * *}$ & 0.8232 & 0.0382 & -5.0893 & $<.001$ \\
\hline \multicolumn{6}{|l|}{ Age } \\
\hline$<25$ & baseline & & & & \\
\hline $25-34$ & -0.0354 & 0.9652 & 0.027 & -1.3123 & 0.1894 \\
\hline $35-44$ & $-0.1016^{* *}$ & 0.9034 & 0.0326 & -3.1153 & 0.0018 \\
\hline $45-54$ & $-0.0739^{*}$ & 0.9288 & 0.037 & -1.9998 & 0.0455 \\
\hline $55-64$ & -0.0768 & 0.9261 & 0.0485 & -1.5827 & 0.1135 \\
\hline$\geq 65$ & -0.0992 & 0.9056 & 0.0647 & -1.5333 & 0.1252 \\
\hline \multicolumn{6}{|l|}{ Gender } \\
\hline Male & baseline & & & & \\
\hline Female & 0.0381 & 1.0388 & 0.0209 & 1.8258 & 0.0679 \\
\hline \multicolumn{6}{|l|}{ Nationality } \\
\hline Non-Swiss & baseline & & & & \\
\hline Swiss & 0.0021 & 1.0021 & 0.0315 & 0.0674 & 0.9462 \\
\hline \multicolumn{6}{|l|}{ Urbanicity } \\
\hline Rural & baseline & & & & \\
\hline Urban & 0.0253 & 1.0256 & 0.0208 & 1.2174 & 0.2235 \\
\hline \multicolumn{6}{|l|}{ Customer Status } \\
\hline Existing Customer & baseline & & & & \\
\hline New Customer & 0.0300 & 1.0304 & 0.0271 & 1.1081 & 0.2678 \\
\hline \multicolumn{6}{|l|}{ Policy Status } \\
\hline Replaced Policy & baseline & & & & \\
\hline New Policy & $0.3187^{* * *}$ & 1.3753 & 0.0269 & 11.8592 & $<.001$ \\
\hline
\end{tabular}

Note: Significance levels for $p$-values: ${ }^{* * *} p \leq .001,{ }^{* *} p \leq .01,{ }^{*} p \leq .05$.

addition, purchasing a new policy is also found to be significant $(\beta=.351, p<.001)$.

When looking at the product-specific characteristics, no significant effects of the years of driving experience and type of vehicle are found to exist. In turn, the age of the vehicle is found to have a highly significant impact. Compared to the baseline category, all other categories, i.e. vehicles of age between 1 and 4 years $(\beta=.210, p<.001), 5$ to 9 years $(\beta=.164, p<.001)$, and more than 10 years $(\beta=.136$, $p<.001)$ are found to have a highly significant positive effect. The likelihood ratio statistic of the model indicates a significant fit $\left(\chi^{2}(19, N=5891)=358.028, p<.001\right)$ with an $R^{2}=.041$.

\section{Household/Liability Insurance}

The results of the survival analysis over the household/liability product are also presented in Table 9. For this product only two significant effects seem to exist. Being 25 to 34 years is found to have a positive effect on the duration compared to the youngest customers, whereas for other age ranges the effect is negative. However the coefficients are not significant. Similarly, the variables gender, nationality and urbanicity showed no significant effect. In turn, being a new customer $(\beta=.124, p<.05)$ and purchasing a new policy $(\beta=.192, p<.01)$ are found to have a positive significant effect on the duration. Living in a couples or family household had a negative impact on the duration, however the effect was not significant. 
From Research to Purchase: Shopping Behaviour in the Insurance Sector

Tabelle 9: Coefficients of the Cox model for the different insurance products.

\begin{tabular}{|c|c|c|c|c|c|c|}
\hline \multirow[b]{2}{*}{ Characteristics } & \multicolumn{2}{|c|}{ Motor } & \multicolumn{2}{|c|}{ Household/liability } & \multicolumn{2}{|c|}{ Travel } \\
\hline & $\beta$ & $\exp (\beta)$ & $\beta$ & $\exp (\beta)$ & $\beta$ & $\exp (\beta)$ \\
\hline \multicolumn{7}{|l|}{ Age } \\
\hline$<25$ & baseline & & baseline & & baseline & \\
\hline $25-34$ & $-0.1123^{*}$ & 0.8937 & 0.0573 & 1.0590 & 0.0652 & 1.0673 \\
\hline $35-44$ & $-0.1538^{*}$ & 0.8574 & -0.0181 & 0.9821 & 0.0351 & 1.0357 \\
\hline $45-54$ & -0.0688 & 0.9335 & -0.0150 & 0.9851 & 0.0079 & 1.0079 \\
\hline $55-64$ & -0.0642 & 0.9378 & -0.0724 & 0.9302 & 0.2061 & 1.2288 \\
\hline$\geq 65$ & -0.1612 & 0.8511 & -0.0443 & 0.9567 & 0.2581 & 1.2945 \\
\hline \multicolumn{7}{|l|}{ Génder } \\
\hline Male & baseline & & baseline & & baseline & \\
\hline Female & $0.0760^{* *}$ & 1.079 & -0.0271 & 0.9732 & -0.0440 & 0.9569 \\
\hline \multicolumn{7}{|l|}{ Nationality } \\
\hline Non-Swiss & baseline & & baseline & & baseline & \\
\hline Swiss & 0.0598 & 1.0616 & -0.0683 & 0.934 & -0.0470 & 0.9541 \\
\hline \multicolumn{7}{|l|}{ Urbanicity } \\
\hline Rural & baseline & & baseline & & baseline & \\
\hline Urban & 0.0171 & 1.0173 & -0.0248 & 0.9755 & 0.0530 & 1.0544 \\
\hline \multicolumn{7}{|l|}{ Customer Status } \\
\hline Existing Customer & baseline & & baseline & & baseline & \\
\hline New Customer & 0.0032 & 1.0032 & $0.1237^{*}$ & 1.1317 & 0.1053 & 1.1110 \\
\hline \multicolumn{7}{|l|}{ Policy Status } \\
\hline Replaced Policy & baseline & & baseline & & baseline & \\
\hline New Policy & $0.3509^{* * *}$ & 1.4204 & $0.1915^{* *}$ & 1.2110 & $0.4698^{* * *}$ & 1.5996 \\
\hline \multicolumn{7}{|c|}{ Drivers License since } \\
\hline$<1$ & baseline & & & & & \\
\hline $1-4$ & 0.0592 & 1.0610 & & & & \\
\hline $5-9$ & 0.0725 & 1.0752 & & & & \\
\hline $10-19$ & 0.1009 & 1.1061 & & & & \\
\hline $20-29$ & 0.0905 & 1.0947 & & & & \\
\hline$\geq 30$ & 0.0472 & 1.0483 & & & & \\
\hline \multicolumn{7}{|l|}{ Type of Vehicle } \\
\hline Motor Cycle & baseline & & & & & \\
\hline Passenger Car & -0.0566 & 0.9450 & & & & \\
\hline \multicolumn{7}{|l|}{ Age of vehicle } \\
\hline$<1$ & baseline & & & & & \\
\hline $1-4$ & $0.2099^{* * *}$ & 1.2335 & & & & \\
\hline $5-9$ & $0.1642^{* * *}$ & 1.1784 & & & & \\
\hline$\geq 10$ & $0.1358^{* * *}$ & 1.1455 & & & & \\
\hline \multicolumn{7}{|l|}{ Type of Household } \\
\hline Singles & & & baseline & & baseline & \\
\hline Couples & & & -0.0932 & 0.9110 & -0.0990 & 0.9057 \\
\hline \multicolumn{7}{|c|}{ Number of Children in Household } \\
\hline No Children & & & baseline & & baseline & \\
\hline 1 Child & & & 0.0001 & 0.9996 & -0.0037 & 0.9963 \\
\hline 2 Children & & & 0.1485 & 1.1601 & -0.0830 & 0.9203 \\
\hline 3 or more Children & & & 0.1119 & 1.1184 & 0.0286 & 1.0290 \\
\hline \multicolumn{7}{|l|}{ Ownership } \\
\hline Owner & & & -0.0764 & 0.9265 & & \\
\hline Renter & & & baseline & & & \\
\hline Sum assured & & & & & & \\
\hline$<30$ & & & baseline & & & \\
\hline $30-44$ & & & 0.0052 & 1.0052 & & \\
\hline $45-59$ & & & 0.0504 & 1.0517 & & \\
\hline $60-74$ & & & 0.0015 & 1.0015 & & \\
\hline $75-89$ & & & -0.1541 & 0.8572 & & \\
\hline $90-104$ & & & 0.0590 & 1.0608 & & \\
\hline $105-124$ & & & -0.1077 & 0.8979 & & \\
\hline $125-149$ & & & -0.1505 & 0.8603 & & \\
\hline$\geq 150$ & & & -0.1233 & 0.8840 & & \\
\hline
\end{tabular}

Note: Significance levels for $p$-values: *** $p \leq .001,{ }^{* *} p \leq .01,{ }^{*} p \leq .05$. 
As well for the further product specific measures no significant effects are found to exist. The likelihood ratio statistic of the model indicates a significant fit $\left(\chi^{2}(23, N=2773)=110.429, p<.001\right)$ with an $R^{2}=.039$.

\section{Travel Insurance}

For the travel insurance product, the effect of age on the duration to purchase is shown to have a positive effect over all age groups, however none of them is statistically significant. Similarly, positive but non significant effect is found for the facts that a customer comes from an urban area or is a new customer. Further, the effects of being a female or having Swiss nationality are found to be negative, but again not significant. A positive and significant effect on the duration to purchase is found only for purchasing a new policy $(\beta=.470, p<.001)$. Finally, no significant effects are found to exist for the product specific measures. The likelihood ratio statistic of the model indicates a significant fit $\left(\chi^{2}(19, N=1127)=35.139, p<.01\right)$ with an $R^{2}=.031$.

\section{Discussion and Implications for Research and Practice}

The goal of this study is to understand multichannel behaviour for non-life insurance customers and in particular to determine which customer characteristics have an effect over the time taken by researchshoppers between product research - conducted on an online channel, i.e. the insurer's website, - and the policy purchase - conducted through an offline channel, i.e. at the agency. Overall, the results reveal that on average customers take 19.5 workdays after looking up for online quotes to make a purchase. Still, lower median value ( 13.5 workdays) indicates that majority of the customers make their decision faster and that only a minority of research-shoppers needs more time to make a purchase.

\section{Product comprehensive analysis}

The results of the survival analysis over the complete dataset show that there are several customer characteristics that have an effect over the duration to purchase of a research-shopper. As expected, insurance products were found to have a significant effect, with customers purchasing motor and household/liability insurance products taking about 5 workdays more compared to those buying a travel insurance. A possible explanation for this effect could come from the lower complexity of travel insurance products in relation to the other two, as there are only a limited number of coverages and options available for such policies. Further, purchasing an insurance coverage for the first time is found to have a positive effect over the duration to purchase. Moreover, this effect is the strongest one over the complete dataset. An explanation for these results might be that in the case of purchasing a new policy the need for coverage against risk is more urgent than in the case of replacing an existing policy, where the coverage partially or fully exists. Finally, a negative effect is found to exist for customers belonging to the age groups between 35 and 54 years old. Assuming that younger customers have less valuables, while older customers already have a good understanding of the insurance products and established patterns of customer behaviour, we hypothesize that middle age groups is undergoing a transition period in terms of their possessions and correspondingly, their insurance needs, and are therefore in need for more time to make a choice regarding 
a purchase of an insurance product. Overall, our results show empirical evidence for differences in the observed customer behaviour which can be explained by differences in some of the customer characteristics. Therefore we state that hypothesis (H1) is partially supported.

\section{Product specific analysis}

The results of the product specific analysis reveal that for the motor and household/liability insurance products distinct characteristics add explanatory value to model. Similar to the model over the complete dataset, for motor insurance product a positive effect of purchasing a new policy is found to exist. In addition, the positive effect of age of vehicle could result from the fact, that people who purchase new cars have a longer waiting period between ordering a car and than getting it delivered. These customers already know the concrete configuration of their future vehicle after ordering it, and in the meantime they search for appropriate insurance coverage through online channels. A further positive effect is found for being a female customer which might be explained by a potentially lower level of knowledge about the product resulting in shorter time before approaching an agent to gain additional explanation. Finally, a negative effect is observed for customers being between 25 and 44 years old with a possible explanation that customers of these age groups purchase more valuable vehicles for the first time and are thus interested in obtaining the best possible coverage which might result in longer research times.

For the household/liability insurance product, again the positive effect of purchasing a new policy is found and is enhanced by being a new customers. Both effects again might be associated with the greater customer needs for insurance coverage thus resulting in shorter duration to purchase. The negative effect of customers living in couples' households we observered might result from the fact that the decision making process to purchase insurance coverage is more complex than in households inhabited by singles. The product specific analysis for travel insurance does not reveal further effects in addition to the overall results and therefore we state that hypothesis (H2) is partially supported.

\section{Implications for Research and Practice}

The results presented in this paper have implications for both researchers and practitioners. For researchers, the results reveal that there are differences in research-shopper behaviour that need a better understanding. Since loosing a customer in the process of multichannel shopping is a major challenge for companies, understanding what drives the duration between online research and store purchase is a subject of relevance. A main implication of the current study is that the survival duration differs among insurance customers and that specific characteristics provide an explanation for this variation. In addition, the results have implications for building predictive models to anticipate customer activities and purchase behaviour. When constructing a prediction model for insurance customers, which predicts not only what and if a customer is likely to purchase, but additionally when the purchase event is likely to happen (Knott et al., 2002), our results provide a summary of relevant predictors.

For practitioners, and particularly those from the insurance sector, this study provides a guideline on how to tackle the challenge of Internet $\rightarrow$ Store shopping behaviour as the most common type of multichannel behaviour. In a contractual setting of insurance sector which enables and demands for customer-base analysis (Fader and Hardie, 2009), the companies could implement a method to daily com- 
pare attributes of online quotes from the research stage to the information from the customer database, thus moving to the trend of customer-centric marketing. For positive matches, leads could be generated and provided further to the sales departments, including the information on how fast a customer is likely to make a decision for a purchase. Such knowledge would enable the sales personnel to focus its resources on those customers who are more likely to purchase fast and not use any resources if the survival probability of a research-shopper has already reached a value close to zero.

\section{Summary and Future Work}

In this paper we address the research-shopper phenomenon in the insurance sector. We investigate which customer and policy characteristics influence the research-shopper behaviour in terms of duration from research online to purchase offline. We conduct an analysis across three common non-life insurance products, motor, household/liability and travel insurance. Our results show that several customer characteristics have a significant effect on the duration to purchase and that these characteristics differ across different products.

This study is limited in some dimensions and thus provides streams for future research. First, the model explains the variation in the duration based only on customer demographics, while further potential factors have been left out. Such factors might improve the explanatory power of the survival models. This could be covered by extending this study based on a customer survey to include measures such as shopping motives, perceived risks and benefits, etc. Second, our hypotheses are tested on a sample from a single company. In order to verify our results, future studies should be based on additional customer samples. Third, we only studied the loyal research-shoppers. Future research could be based on a sample, which contains data for competitive research-shoppers as well, and enables analysis of the potential impact of the research-shopper type on the duration to purchase. Finally, an additional valid question would be if there are loyal research-shoppers for insurance policies at all. With the presence of online aggregators and their ease of use and transparency it is simple to imagine that research-shoppers compare insurance products across several companies before each purchase. Thus, more research is required on this topic in order to address the problem of customer retention in overall.

\section{Literatur}

Ansari, A., C. F. Mela, and S. A. Neslin (2008), Customer channel migration, Journal of Marketing Research, 45(1), p.60-76.

Balasubramanian, S., R. Raghunathan, and V. Mahajan (2005), Consumers in a multichannel environment: Product utility, process utility, and channel choice, Journal of Interactive Marketing, 19(2), p.12-30.

Berger, A., J. Cummins, and M. Weiss (1997), The Coexistence of Multiple Distribution Systems for Financial Services: The Case of Property-Liability Insurance, The Journal of Business, 70(4), p.515546 . 
Bhatnagar, A. and S. Ghose (2004), A latent class segmentation analysis of e-shoppers, Journal of Business Research, 57(7), p.758-767.

Cather, D. a. and V. Howe (1989), Conflict and Channel Management in Property-Liability Distribution Systems, The Journal of Risk and Insurance, 56(3), p.535-543.

Chiu, H.-C., Y.-C. Hsieh, J. Roan, K.-J. Tseng, and J.-K. Hsieh (2011), The challenge for multichannel services: Cross-channel free-riding behavior, Electronic Commerce Research and Applications, 10(2), p.268-277.

Cox, D. (1972), Models and Life-Tables Regression, Journal of the Royal Statistical Society Series B, $34(2)$, p.187-220.

Dall'Olmo Riley, F., D. Scarpi, and A. Manaresi (2009), Purchasing services online: a two-country generalization of possible influences, Journal of Services Marketing, 23(2), p.92-102.

Elliott, M. T., F. Q. Fu, and P. S. Speck (2012), Information Search and Purchase Patterns in a Multichannel Service Industry, Services Marketing Quarterly, 33(4), p.292-310.

Fader, P. S. and B. G. Hardie (2009), Probability Models for Customer-Base Analysis, Journal of Interactive Marketing, 23(1), p.61-69.

Gupta, A., B.-C. Su, and Z. Walter (2004), An Empirical Study of Consumer Switching from Traditional to Electronic Channels: A Purchase-Decision Process Perspective, International Journal of Electronic Commerce, 8(3), p.131-161.

Heitz-Spahn, S. (2013), Cross-channel free-riding consumer behavior in a multichannel environment: An investigation of shopping motives, sociodemographics and product categories, Journal of Retailing and Consumer Services, 20(6), p.570-578.

Knott, A., A. Hayes, and S. A. Neslin (2002), Next-product-to-buy models for cross-selling applications, Journal of Interactive Marketing, 16(3), p.59-75.

Konus, U., P. Verhoef, and S. Neslin (2008), Multichannel Shopper Segments and Their Covariates, Journal of Retailing, 84(4), p.398-413.

Kumar, V. and R. Venkatesan (2005), Who are the multichannel shoppers and how do they perform?: Correlates of multichannel shopping behavior, Journal of Interactive Marketing, 19(2), p.44-62.

Kushwaha, T. and V. Shankar (2013), Are multichannel customers really more valuable? The moderating role of product category characteristics, Journal of Marketing, 77(4), p.67-85.

Li, H., C. Kuo, and M. G. Rusell (1999), The Impact of Perceived Channel Utilities, Shopping Orientations, and Demographics on the Consumer's Online Buying Behavior, Journal of Computer-Mediated Communication, 5(2), p.0-0.

Liu, X. (2012), Survival Analysis: Models and Applications. Wiley. 
McKinsey (2012), Winning Share and Customer Loyalty in Auto Insurance, Insights from McKinsey's Auto Insurance Customer Insights Research.

Neslin, S. A., D. Grewal, R. Leghorn, V. Shankar, M. L. Teerling, J. S. Thomas, and P. C. Verhoef (2006), Challenges and Opportunities in Multichannel Customer Management, Journal of Service Research, $9(2)$, p.95-112.

Neslin, S. A. and V. Shankar (2009), Key Issues in Multichannel Customer Management: Current Knowledge and Future Directions, Journal of Interactive Marketing, 23(1), p.70-81.

Noble, S., D. Griffith, and M. Weinberger (2005), Consumer derived utilitarian value and channel utilization in a multi-channel retail context, Journal of Business Research, 58(12), p.1643-1651.

Nunes, P. F. and F. V. Cespedes (2003), The Customer Has Escaped, Harvard Business Review, 81, p.96-105.

Rangaswamy, A. and G. Van Bruggen (2005), Opportunities and challenges in multichannel marketing: An introduction to the special issue, Journal of Interactive Marketing, 19(2), p.5-11.

Schoenbachler, D. D. and G. L. Gordon (2002), Multichannel shopping: understanding what drives channel choice, Journal of Consumer Marketing, 19(1), p.42-53.

Soopramanien, D. G. and A. Robertson (2007), Adoption and usage of online shopping: An empirical analysis of the characteristics of buyers browsers and non-internet shoppers, Journal of Retailing and Consumer Services, 14(1), p.73-82.

Stone, M., B. Foss, and L. Machtynger (1997), The UK consumer direct insurance industry: a role model for relationship management?, Long Range Planning, 30(2), p.353-363.

Stone, M., M. Hobbs, and M. Khaleeli (2002), Multichannel customer management: The benefits and challenges, The Journal of Database Marketing, 10(1), p.39-52.

SwissRe (2012), Digital distribution in insurance: A quiet revolution, Sigma, 2.

Thomas, J. S. and U. Y. Sullivan (2005), Managing marketing communications with multichannel customers, Journal of Marketing, 69(4), p.239-251.

Trigo-Gamarra, L. (2008), Reasons for the coexistence of different distribution channels: An empirical test for the German insurance market, The Geneva Papers on Risk and Insurance-Issues and Practice, 33(3), p.389-407.

Trigo-Gamarra, L. and C. Growitsch (2010), Comparing Single-and Multi-Channel Distribution Strategies in the German Life Insurance Market: An Analysis of Cost and Profit Efficiency, Schmalenbach Business Review, 62, p.401-417.

Van Baal, S. and C. Dach (2005), Free riding and customer retention across retailers' channels, Journal of Interactive Marketing, 19(2), p.75-85. 
Venkatesan, R., V. Kumar, and N. Ravishanker (2007), Multichannel Shopping: Causes and Consequences, Journal of Marketing, 71(2), p.114-132.

Verhoef, P. C., S. a. Neslin, and B. Vroomen (2007), Multichannel customer management: Understanding the research-shopper phenomenon, International Journal of Research in Marketing, 24(2), p.129-148.

Yang, A. S. (2015), Measuring Self-Service Technology Latent Difficulties: Insurance Decisions on Utilitarian and Hedonic Influences, Asia-Pacific Journal of Risk and Insurance, 9(1), p.1-33. 